\title{
Regulation of $\alpha$-Synuclein Expression in Limbic and Motor Brain Regions of Morphine-Treated Mice
}

\author{
Barbara Ziolkowska, ${ }^{1}$ Agnieszka Gieryk, ${ }^{1}$ Wiktor Bilecki, ${ }^{1}$ Agnieszka Wawrzczak-Bargiela, ${ }^{1}$ Krzysztof Wedzony, ${ }^{1}$ \\ Agnieszka Chocyk, ${ }^{1}$ Patria E. Danielson, ${ }^{2}$ Elizabeth A. Thomas, ${ }^{2}$ Brian S. Hilbush, ${ }^{3}$ J. Gregor Sutcliffe,${ }^{2}$ and \\ Ryszard Przewlocki ${ }^{1}$ \\ ${ }^{1}$ Institute of Pharmacology, Polish Academy of Sciences, 31-343 Kraków, Poland, and ${ }^{2}$ The Scripps Research Institute and ${ }^{3}$ Digital Gene Technologies, La \\ Jolla, California 92037
}

\begin{abstract}
Chronic exposure to opiates produces dependence and addiction, which may result from neuroadaptations in the dopaminergic reward pathway and its target brain regions. The neuronal protein $\alpha$-synuclein has been implicated in neuronal plasticity and proposed to serve as a negative regulator of dopamine neurotransmission. Thus, $\alpha$-synuclein could mediate some effects of opiates in the brain. The present study investigated the influence of acute and chronic morphine administration on $\alpha$-synuclein mRNA and protein expression in the brains of mice. Downregulation of $\alpha$-synuclein mRNA was observed in the basolateral amygdala, dorsal striatum, nucleus accumbens, and ventral tegmental area of mice withdrawn from chronic morphine treatment. The changes were the most pronounced after longer periods of withdrawal ( $48 \mathrm{~h}$ ). In contrast, levels of $\alpha$-synuclein protein, as assessed by Western blotting, were significantly increased in the amygdala and striatum/accumbens (but not in the mesencephalon) of morphine-withdrawn mice. In both brain regions, levels of $\alpha$-synuclein were elevated for as long as 2 weeks after treatment cessation. Because $\alpha$-synuclein is a presynaptic protein, the detected opposite changes in its mRNA and protein levels are likely to take place in different populations of projection neurons whose somata are in different brain areas. Axonal localization of $\alpha$-synuclein was confirmed by immunofluorescent labeling. An attempt to identify postsynaptic neurons innervated by $\alpha$-synuclein-containing axon terminals revealed their selective apposition to calbindin D28Knegative projection neurons in the basolateral amygdala. The observed changes in $\alpha$-synuclein levels are discussed in connection with their putative role in mediating suppression of dopaminergic neurotransmission during opiate withdrawal.
\end{abstract}

Key words: opiate; drug dependence; withdrawal; $\alpha$-synuclein; gene expression; neuronal plasticity; neurotoxicity

\section{Introduction}

Chronic exposure to opiates leads to development of adaptive changes in the brain, which underlie opiate dependence and addiction. Effects of opiates on the noradrenergic and dopaminergic systems are considered crucial for these phenomena. Whereas the noradrenergic system seems to be involved mainly in the physical dependence to opiates, the dopaminergic system is implicated in the rewarding and reinforcing actions of the drugs (Di Chiara and North, 1992; Hyman and Malenka, 2001; Nestler, 2004). Thus, opiate-produced alterations in dopaminergic neurotransmission might be responsible for disturbances in motivational and emotional processes, which underlie addiction. Opiates, when administered acutely, indirectly stimulate dopaminergic neurons located in the ventral mesencephalon, which innervate several forebrain regions, including the nucleus accumbens, dorsal striatum, amygdala, and prefrontal cortex (Di Chiara

\footnotetext{
Received Dec. 8, 2003; revised April 11, 2005; accepted April 12, 2005.

This work was supported by State Committee for Scientific Research (Warsaw, Poland) Grants 6 P05A 10720 and PBZ-KBN-033/P05/2000 and by Grant GM32355 from The Scripps Research Institute. We thank Michal Korostynski for assistance in preparing the figures.

Correspondence should be addressed to Ryszard Przewlocki, Institute of Pharmacology, Polish Academy of Sciences, Smetna 12,31-343 Kraków, Poland. E-mail: nfprzewl@cyf-kr.edu.pl.

DOI:10.1523/JNEUROSCI.4376-04.2005

Copyright $\odot 2005$ Society for Neuroscience $\quad$ 0270-6474/05/254996-08\$15.00/0
}

and North, 1992). Neuroadaptations in presynaptic and postsynaptic parts of these dopaminergic projections, some of which have been identified, may account for lasting behavioral effects of prolonged opiate use (Sklair-Tavron et al., 1996; Hyman and Malenka, 2001; Nestler, 2001, 2004).

It has been demonstrated recently that the neuronal protein $\alpha$-synuclein might be an important regulator of dopamine function. $\alpha$-Synuclein is an abundant and ubiquitous protein that accumulates in presynaptic terminals (Iwai et al., 1995; Clayton and George, 1998, 1999). Although it has been implicated mainly in neurodegeneration, especially in the pathogenesis of Parkinson's disease (Lotharius and Brundin, 2002), some its physiological functions in normal brain have been proposed. They include roles in synaptic vesicle cycling and synaptic plasticity (Clayton and George, 1998, 1999; Vekrellis et al., 2004). $\alpha$-Synuclein is expressed at high levels in dopaminergic neurons, and it has been shown to downregulate the expression and inhibit the activity of tyrosine hydroxylase, the key enzyme in dopamine synthesis (Perez et al., 2002; Baptista et al., 2003), to decrease expression of other enzymes involved in dopamine synthesis (Baptista et al., 2003), and to affect dopamine transporter activity (Lee et al., 2001; Wersinger and Sidhu, 2003). In addition, studies in $\alpha$-synuclein knock-out mice revealed that it might inhibit refilling and reduce storage capacity of presynaptic dopamine- 
containing vesicles, thus serving as a negative regulator of dopaminergic neurotransmission (Abeliovich et al., 2000; Yavich et al., 2004).

The above properties suggest that $\alpha$-synuclein could be potentially involved in the effects exerted by opiates on the dopaminergic reward pathway. Moreover, in a pilot experiment using the total gene expression analysis technique (Sutcliffe et al., 2000), we found that $\alpha$-synuclein mRNA was downregulated by chronic morphine administration in the mouse amygdala, a target region of dopaminergic projection, which plays an essential role in reinstatement of opiate-reinforced behaviors (Fuchs and See, 2002; Shalev et al., 2002). Thus, the present study was undertaken to assess the influence of morphine treatment on levels of $\alpha$-synuclein mRNA and protein at presynaptic and postsynaptic sites of the dopamine pathway in the mouse brain. Distribution of $\alpha$-synuclein was also studied at the cellular level, and its relationship to calbindin D28K (CB), a marker of some neuronal populations, was defined in the striatum and amygdala.

\section{Materials and Methods}

Animal treatment

Male C57BL/6 mice (bred in the Animal House of the Children's Hospital of the Jagiellonian University, Kraków, Poland) weighing from 25 to $30 \mathrm{~g}$ were used throughout the experiments. The mice were kept under standard conditions on a $12 \mathrm{~h}$ light/dark cycle with ad libitum access to food and water. The animal protocols used in the study were approved by the local Bioethics Commission working at the Institute of Pharmacology, Polish Academy of Sciences (Kraków, Poland).

Morphine (morphine hydrochloride; Polfa, Kutno, Poland) was administered to the mice using the following paradigms.

Acute administration of morphine. Animals were treated with a single dose of morphine (10 mg/kg, i.p.) and killed by decapitation after 4,8 , or $48 \mathrm{~h}$. The control groups were injected with saline and killed after 4 or $48 \mathrm{~h}$.

Chronic administration of morphine. Animals were injected intraperitoneally with increasing doses of morphine twice daily for $9 \mathrm{~d}$. Single doses were administered every $12 \mathrm{~h}$ according to the following order (in $\mathrm{mg} / \mathrm{kg}$ ): 10 once, 15 once, 20 once, 25 once, 30 once, 35 once, 40 once, 45 once, 50 three times, 75 three times, and 100 four times. A control group was treated with saline according to the same schedule and killed $4 \mathrm{~h}$ after the last injection. As a result of chronic morphine treatment, an average body-weight loss of $1.06 \mathrm{~g}$ was observed, whereas mice of the control group gained $0.72 \mathrm{~g}$, on average, during the treatment period.

Mice of the morphine-treated group were killed by decapitation 4, 24, or $48 \mathrm{~h}$ after the last injection. In some of the morphine-treated mice, withdrawal was precipitated by injection of naloxone $(4 \mathrm{mg} / \mathrm{kg}$, i.p.; Sigma, St. Louis, MO) $2 \mathrm{~h}$ after the last morphine injection. These mice were killed $4 \mathrm{~h}$ after naloxone administration. In addition, a long, spontaneous withdrawal paradigm was used in one experiment, in which mice were killed 2 weeks after the last dose of morphine or saline.

\section{In situ hybridization and image analysis}

After decapitation, the brains were removed and frozen on dry ice. Then they were cut into $12-\mu \mathrm{m}$-thick coronal sections on a cryostat microtome (CM 3050 S; Leica, Nussloch, Germany), the sections were thaw mounted on gelatin-chromium potassium sulfate-coated slides and processed for in situ hybridization according to the method of Young et al. (1986). Briefly, the sections were fixed with $4 \%$ paraformaldehyde, washed with PBS, and acetylated by incubation with $0.25 \%$ acetic anhydrite (in $0.1 \mathrm{~m}$ triethanolamine and $0.9 \%$ sodium chloride). The sections were then dehydrated using increasing concentrations of ethanol (70$100 \%$ ), treated with chloroform for $5 \mathrm{~min}$, and rehydrated with decreasing concentrations of ethanol.

The sections were hybridized for $\sim 15 \mathrm{~h}$ at $37^{\circ} \mathrm{C}$ with an oligonucleotide probe complementary to nucleotides $329-377$ of the mouse $\alpha$-synuclein cDNA (Hong et al., 1998) (5'-TGTCTTCTGAGCGACTGCTGTCACACCAGTCACCACTGCTCCTCCAACA- $3^{\prime}$ ). The probe was labeled with $\left[{ }^{35} \mathrm{~S}\right]$ deoxyATP by the 3 '-tailing reaction using terminal transferase (Roche Diagnostics, Mannheim, Germany).

After hybridization, the slices were washed three times for $20 \mathrm{~min}$ with $1 \times \mathrm{SSC} / 50 \%$ formamide at $40^{\circ} \mathrm{C}$ and twice for 50 min with $1 \times \mathrm{SSC}$ at room temperature. Then, the slices were dried and exposed to Fujifilm (Tokyo, Japan) PhosphorImager imaging plates for $4-5 \mathrm{~d}$. The hybridization signal was digitized using the Fujifilm BAS-5000 PhosphorImager and the Image Reader software.

In situ hybridization signal was analyzed using the MCID Elite system (Imaging Research, St. Catharines, Ontario, Canada). Mean signal density, expressed in photostimulated luminescence units per square millimeter, was measured in selected brain regions in the Fujifilm BAS-5000 images. The regions included the following: the substantia nigra, ventral tegmental area (VTA), dorsal striatum, nucleus accumbens core and shell, lateral and basolateral nuclei of the amygdala, and the motor cortex. For each brain structure, data were collected from at least four sections per animal, bilaterally. Background signal was measured over the white matter (corpus callosum, dorsal hippocampal commissure) and subtracted from the hybridization signal in the regions of interest. Final results were expressed as a percentage of mean value in the control group.

\section{Tissue dissection}

After decapitation, brains were removed from the skulls and dissected rapidly. We collected samples containing (1) the rostral part of the caudate/putamen plus the nucleus accumbens (referred to as striatum/accumbens), (2) the amygdala (the tissue $\sim 0.5 \mathrm{~mm}$ below the rhinal fissure, including the majority of the amygdalar nuclei located between the piriform cortex on one side and the optic tract and ventral part of the lateral ventricles, substantia innominata, and ventral border of the caudatoputamen on the other), and (3) the ventral mesencephalon. Tissue samples were frozen on dry ice immediately after dissection and stored at $-70^{\circ} \mathrm{C}$ until RNA or protein extraction.

\section{$R N A$ isolation and reverse transcription real-time PCR}

Total RNA was isolated from the tissue by acid guanidinium thiocyanatephenol-chloroform extraction. The original method described by Chomczynski and Sacchi (1987) was modified in such a way that, after the phenol/chloroform/isoamyl alcohol extraction, the water phase was reextracted with an equal volume of chloroform/isoamyl alcohol, precipitated with an equal volume of isopropanol, dried, and dissolved in water. Although tissues from different animals were extracted separately, additional steps were performed on two to three pooled equivalent RNA samples.

The reverse transcription (RT) and real-time PCRs were performed in one step using the QuantiTect SYBR Green RT-PCR kit (Qiagen, Hilden, Germany) and the iCycler real-time PCR device (Bio-Rad, Hercules, CA). The following primer sequences were used: $5^{\prime}$-TTT CAA AGT CTT CCA TCA GCA-3' (5' primer) and 5'-GCA ACA AAA AGA AAA CGA TGA A-3' (3' primer). The results were analyzed by applying the iCycler software (Bio-Rad).

Specificity of RT-PCR products was validated by making a melting temperature curve and further confirmed by agarose gel electrophoresis. Threshold value (by default, 10 times the mean SD of fluorescence in all wells over the baseline cycles) was set for all samples in the exponential phase of PCR. Thus, the data obtained in the course of RT-PCR represent the cycle in which the signal from a sample reaches the threshold value. To calculate relative amounts of the product in individual samples, a standard curve (a series of template dilutions) was constructed and subjected to RT-PCR along with experimental samples. Differences in the fluorescence of discrete samples were transformed with respect to control samples and presented as percentage of control.

\section{Western blot}

Tissue samples were homogenized in hot $2 \%$ SDS, boiled for $8 \mathrm{~min}$, and cleared by centrifugation $(20,800 \times g$ for $30 \mathrm{~min})$. Protein concentration in the supernatant was determined using the BCA Protein Assay kit (Sigma). Samples (containing $65 \mu \mathrm{g}$ of protein) were heated for $10 \mathrm{~min}$ at $95^{\circ} \mathrm{C}$ in loading buffer ( 50 mu Tris- $\mathrm{HCl}$, 2\% SDS, $2 \% \beta$-mercaptoethanol, $8 \%$ glycerol, and $0.1 \%$ bromophenol blue) and resolved by SDS-PAGE on $12 \%$ polyacrylamide gels. The amount of protein per lane was optimized in pilot 
studies, in which Western blots were performed using different amounts of protein per sample $(20-150 \mu \mathrm{g})$ extracted from each experimental brain region. For quantitative analysis of $\alpha$-synuclein, the amount of total protein was chosen, for which twofold differences in protein content were linearily reflected by the assay. After the gel electrophoresis, proteins were electrophoretically transferred to polyvinylidene difluoride membranes (Roche $\mathrm{Di}$ agnostics). To control equal gel loading, gels were stained with Coomassie brilliant blue R250 after protein transfer, and intensity of the staining was compared between lanes. The blots were blocked using 5\% albumin (Sigma) in Tris-buffered saline (TBS) for $1 \mathrm{~h}$ and incubated overnight at $4^{\circ} \mathrm{C}$ with the sheep anti- $\alpha$-synuclein polyclonal antibody (1:500 dilution; Abcam, Cambridge, UK). The blots were then incubated with an alkaline phosphataseconjugated secondary antibody (donkey anti-sheep IgG; Abcam) at a dilution of 1:1000 for $1 \mathrm{~h}$ at room temperature. After three $15 \mathrm{~min}$ washes in TBS and $0.1 \%$ Tween 20 and one wash in TBS, immunocomplexes were detected using the CDP-Star, ready-to-use (Roche Diagnostics) chemiluminescent reagent and visualized by applying the Fujifilm LAS-1000 fluorimager system. Relative levels of immunoreactivity were quantified using the Fujifilm software Image Gauge.

\section{Immunohistochemistry}

Mice were anesthetized with Equithesin (1.2\% w/v pentobarbital, 5.3\% $\mathrm{w} / \mathrm{v}$ chloral hydrate, $2.7 \% \mathrm{w} / \mathrm{v}$ magnesium sulfate, $49.5 \% \mathrm{v} / \mathrm{v}$ propylene glycol, and $12.5 \% \mathrm{v} / \mathrm{v}$ ethanol) and perfused transcardially with $80 \mathrm{ml}$ of saline followed by $80 \mathrm{ml}$ of $4 \%$ paraformaldehyde (PF) in $0.1 \mathrm{M}$ PBS. Brains were removed from the skulls, postfixed in $\mathrm{PF}$ for $4 \mathrm{~h}$ at $4^{\circ} \mathrm{C}$, and sectioned on a vibratome (VT1000S; Leica) into 50- $\mu$ m-thick coronal sections. In initial nonfluorescent labeling experiments, the sections were washed three times for $5 \mathrm{~min}$ in PBS and incubated for 15 min with 3\% hydrogen peroxide and 20\% methanol in PBS. After three washes in PBS, they were placed for $1 \mathrm{~h}$ in a solution of $1 \%$ Triton X-100 and 3\% donkey serum in PBS. The sections were then incubated for $\sim 60 \mathrm{~h}$ at $4^{\circ} \mathrm{C}$ with the primary anti- $\alpha$-synuclein antibody diluted at 1:300 (sheep anti- $\alpha$ synuclein polyclonal antibody; Abcam) in PBS with 3\% donkey serum and $0.1 \%$ Triton X-100. After three 10 min washes in PBS, the slices were incubated for $1 \mathrm{~h}$ with biotin-conjugated secondary antibody (donkey anti-sheep; 1:500 dilution; Abcam) and visualized with a Vectastain Elite ABC kit (Vector Laboratories, Burlingame, $\mathrm{CA}$ ) according to the instructions of the manufacturer and with diaminobenzidine as a chromogen. For double-immunofluorescent labeling, the sections, obtained as described above, were placed for $1 \mathrm{~h}$ in the blocking buffer, which contained $3 \%$ donkey serum in $0.01 \mathrm{M} \mathrm{PBS}$ and $1 \%$ Triton X-100. Subsequently, the sections were placed for $60 \mathrm{~h}$ at $4^{\circ} \mathrm{C}$ in a mixture of primary antibodies against $\alpha$-synuclein (1:300 dilution; Abcam) and calbindin D28K (mouse monoclonal IgG1 to calbindin D28K; 1:10,000 dilution; Swant, Bellinzona, Switzerland) in the blocking buffer with a decreased concentration of Triton X-100 (0.1\%). After incubation with the primary antibodies, the sections were washed and placed for $2 \mathrm{~h}$ (at room temperature in total darkness) in a mixture of secondary antisera (diluted to a final concentration in $0.01 \mathrm{~m}$ PBS containing 3\% normal donkey serum and $0.1 \%$ Triton X-100) visualizing $\alpha$-synuclein and calbindin D28K, respectively: donkey anti-sheep IgG conjugated with Texas Red (1:500 dilution; Abcam) or donkey anti-mouse IgG conjugated with cyanine 2 (Cy2) (1:300 dilution; Jackson ImmunoResearch, West Grove, PA). Sections labeled with fluorescent markers were examined and photographed using a Leica DM LB microscope with an epifluorescent attachment and dedicated $\mathrm{Cy} 2$ and Texas Red narrow-band filters. Images were captured using a Photometrics (Tucson, AZ) CoolSNAP FX camera, and MetaMorph (Universal Imaging, Downingtown, PA) software was used for colocalization analysis.

\section{Statistical analysis}

Statistical analysis of the obtained results was performed using one-way ANOVA followed by Tukey's post hoc test. In the experiments in which there were only two groups of data, the unpaired two-tailed Student's $t$ test was used.

\section{morphine withdrawal $48 \mathrm{~h}$ (cM48 group)}

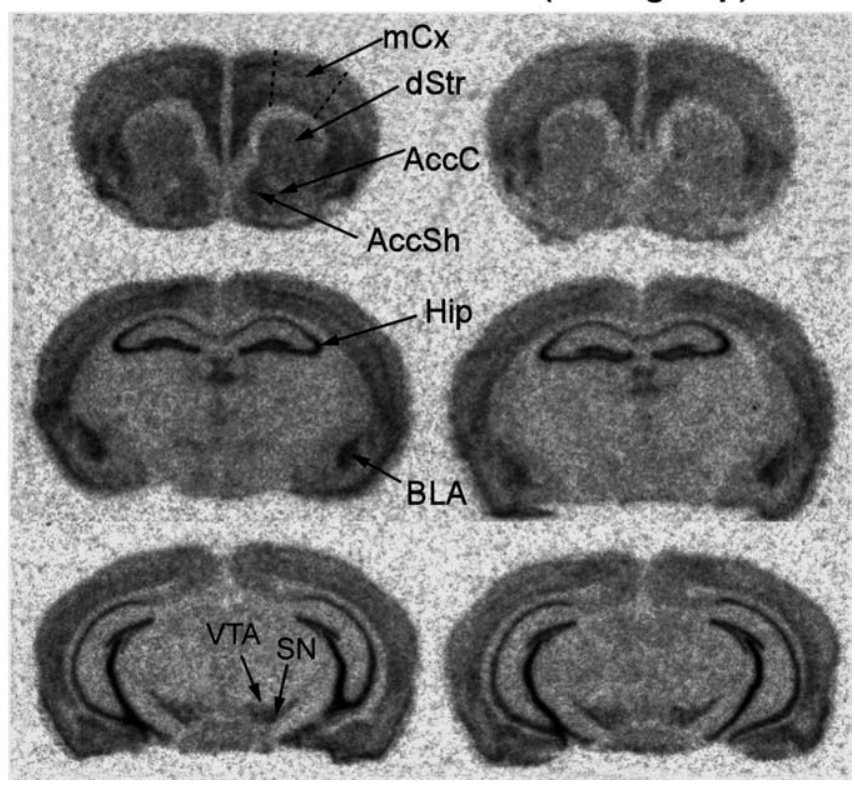

Figure 1. In situ hybridization autoradiograms showing $\alpha$-synuclein mRNA signal in the brains of control mice and mice subjected to chronic morphine treatment followed by $48 \mathrm{~h}$ of withdrawal. AccC, Nucleus accumbens core; AccSh, nucleus accumbens shell; dStr, dorsal striatum; Hip, hippocampus; $m C x$, motor cortex; SN, substantia nigra. Note the reduction in the signal densities in the dStr, AccC, AccSh, BLA, and cortex.

\section{Results}

\section{Distribution of $\alpha$-synuclein mRNA and effects of morphine} treatment on $\alpha$-synuclein mRNA levels

Distribution of $\alpha$-synuclein mRNA was studied by in situ hybridization. The relative intensities of the obtained hybridization signal in discrete brain regions were in agreement with previous reports (Maroteaux and Scheller, 1991; Nakajo et al., 1994; Hong et al., 1998; Petersen et al., 1999). Expression of $\alpha$-synuclein in the brain proved to be high and widespread, with the highest mRNA levels being observed in the pyramidal cell layer of the hippocampus, the granular cell layer of the dentate gyrus, the basolateral amygdala (BLA), the deep layers of the neocortex, and the medial habenular nucleus (Fig. 1). High expression was also found in the dopaminergic cell-body fields: the substantia nigra pars compacta and VTA (Fig. 1). Within the limbic forebrain regions, particularly high levels of $\alpha$-synuclein mRNA were observed in the lateral and basolateral nuclei of the amygdala, and only slightly lower levels were seen in the basomedial amygdaloid nucleus. Strong $\alpha$-synuclein expression was also detected in the anterior cortical nucleus of the amygdala, whereas in the other amygdaloid regions, the expression did not show marked differences compared with surrounding tissue. The striatum and nucleus accumbens showed moderate intensity of $\alpha$-synuclein hybridization signal displaying a slight lateral-to-medial gradient, with higher levels occurring in the medial part of the dorsal striatum (particularly in the dorsomedial region) and the shell of the nucleus accumbens (Fig. 1).

Quantitative in situ hybridization analysis was performed in mice treated acutely or chronically with morphine. No significant changes in $\alpha$-synuclein mRNA levels were detected in the substantia nigra in any group of morphine-treated mice, whereas in the VTA, a small but statistically significant decrease was ob- 

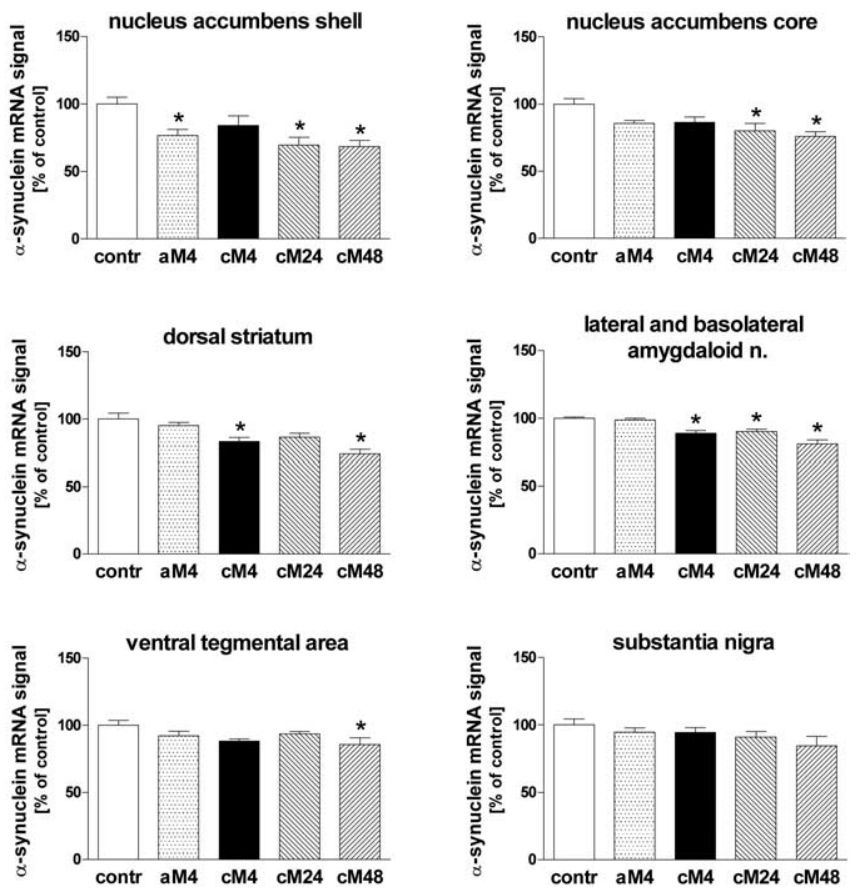

Figure 2. The influence of morphine treatment on $\alpha$-synuclein mRNA in situ hybridization signal densities in subregions of the striatum/accumbens, amygdala, and ventral mesencephalon. contr, Control group injected with saline; aM4, group injected acutely with morphine and killed after 4 h; cM4, cM24, and cM48, groups treated chronically with morphine and killed 4, 24, and $48 \mathrm{~h}$ after the last injection, respectively; $\mathrm{n}$., nuclei. The results are presented as mean \pm SEM (expressed as percentage of control) of seven animals per group. Asterisk indicates statistical significance ( $p<0.05$ or less) versus control group (ANOVA, followed by Tukey's test).

served in animals treated chronically with morphine and withdrawn from the opiate for $48 \mathrm{~h}$ (Figs. 1, 2).

Within the amygdala, the $\alpha$-synuclein mRNA in situ hybridization signal was analyzed jointly in the lateral and basolateral nuclei. $\alpha$-Synuclein gene expression was found to be decreased after chronic morphine administration and further suppressed (by up to 20\%) in the period from 24 to $48 \mathrm{~h}$ of withdrawal (Figs. $1,2)$. A trend toward the reduction of $\alpha$-synuclein mRNA levels was also observed in all examined striatal regions: the dorsal striatum and nucleus accumbens core and shell of morphine-treated mice. Statistically significant declines were found in the dorsal striatum and the shell of the nucleus accumbens $4 \mathrm{~h}$ after either single or chronic morphine administration. A more consistent and profound decrease in the $\alpha$-synuclein mRNA signal density (by up to 30\%) was observed in all three striatal regions 24 and $48 \mathrm{~h}$ after cessation of chronic morphine treatment (Figs. 1, 2). Similar effects were found in the motor cortex (Fig. 1; quantitative data not shown).

To confirm the changes in $\alpha$-synuclein expression by another technique, $\alpha$-synuclein mRNA levels were measured in some morphine-treated groups by quantitative RT-PCR. Samples containing the entire amygdala or the striatum plus the nucleus accumbens were used in that experiment. A profound reduction (by $50-65 \%$ ) of the $\alpha$-synuclein mRNA concentration was observed in both aforementioned brain regions in mice withdrawn for $4 \mathrm{~h}$ from chronic morphine administration and within $4 \mathrm{~h}$ of naloxone-precipitated withdrawal (Fig. 3). Even a single injection of morphine tended to downregulate the $\alpha$-synuclein gene expression 4 and $8 \mathrm{~h}$ after injection, but this effect reached statistical significance only in the striatum/accumbens at $8 \mathrm{~h}$ (Fig. 3). The higher magnitude of the obtained effects, compared with
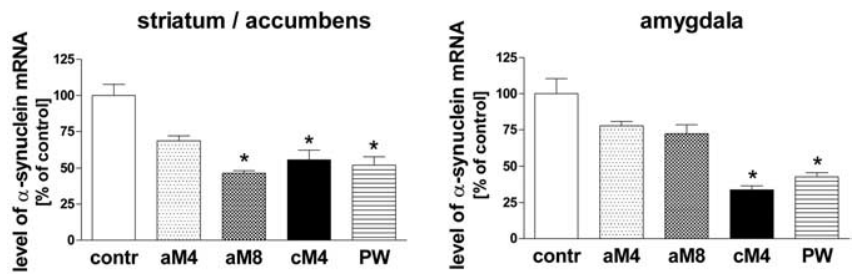

Figure 3. The influence of morphine treatment on the levels of $\alpha$-synuclein mRNA as measured in the mouse striatum and amygdala by real-time RT-PCR. contr, Control group; aM4, aM8, groups injected acutely with morphine and killed 4 and $8 \mathrm{~h}$ after the drug administration, respectively; cM4, group treated chronically with morphine and killed $4 \mathrm{~h}$ after the last injection; PW, precipitated withdrawal group. The results are presented as mean \pm SEM (expressed as percentage of control) of three samples (each derived from 2 to 3 animals). Asterisk indicates statistical significance ( $p<0.05$ or less) versus control group [ANOVA, followed by Tukey's test $(n=3)]$.

those detected by the in situ analysis, was likely attributable to the higher accuracy of the RT-PCR method in reflecting quantitative changes.

\section{Influence of morphine treatment on $\alpha$-synuclein protein levels}

To find out whether downregulation of $\alpha$-synuclein mRNA was accompanied by corresponding changes in protein levels, Western blot analysis was performed on dissected tissue samples of the striatum/accumbens, amygdala, and ventral mesencephalon. Originally, three groups were included in the experiment: mice withdrawn from chronic morphine treatment for 4 and $48 \mathrm{~h}$ (in which decreases in $\alpha$-synuclein mRNA levels had been most pronounced) and the chronic saline control. No significant changes in $\alpha$-synuclein protein levels were found in any brain region $4 \mathrm{~h}$ after the last chronic morphine dose, but the $\alpha$-synuclein levels were markedly elevated by 200 and $80 \%$, respectively, in the striatum/accumbens and amygdala of mice withdrawn from morphine for $48 \mathrm{~h}$ (Fig. 4). No changes were observed in the mesencephalon in this animal group (Fig. 4). After this unexpected finding that withdrawal from chronic morphine produced accumulation of $\alpha$-synuclein in the forebrain, we checked whether a single dose of morphine could evoke a similar effect. However, no changes in $\alpha$-synuclein levels were observed in the striatum/accumbens, amygdala, or mesencephalon at any time point, up to $48 \mathrm{~h}$, after an acute morphine injection (Fig. 4).

Because the increase in $\alpha$-synuclein levels in the forebrain regions was apparent only after cessation of chronic morphine treatment, we performed an additional experiment to find out whether this effect could persist for longer periods of time. In mice withdrawn from chronic opiate for 2 weeks, $\alpha$-synuclein levels in the striatum/accumbens and amygdala were still significantly elevated, although to a smaller degree than in the $48 \mathrm{~h}$ withdrawal group (by $\sim 60$ and 50\%, respectively) (Fig. 4). Again, the protein levels in the mesencephalon remained unchanged at that time point (Fig. 4).

\section{Distribution of $\alpha$-synuclein immunoreactivity and its} relationship to calbindin D28K-immunoreactive neurons in the striatum, nucleus accumbens, and amygdala

$\alpha$-Synuclein was visualized in the mouse-brain sections by immunohistochemistry using the peroxidase-diaminobenzidine color reaction (data not shown) or immunofluorescent labeling with Texas Red. In nearly all examined brain regions, the protein was detectable only in the neuropil (Figs. 5, 6). Bands of distinctly and strongly labeled fibers were detected in the hippocampus; 
their distribution was consistent with previous reports (Maroteaux and Scheller, 1991; Nakajo et al., 1994). Some sparse cells with somata showing $\alpha$-synuclein immunoreactivity were found only in the septum and in the substantia nigra pars compacta. The labeled cells had a neuronal appearance, and the staining was strong in the cytoplasm (including proximal neurites) and weaker in the nucleus. Localization of some $\alpha$-synuclein-immunoreactive cell bodies in the substantia nigra pars compacta may suggest that these were dopaminergic neurons. Nevertheless, only a few labeled cells per section could be observed in this region, which indicates that $\alpha$-synuclein is essentially absent from dopaminergic neuronal somata. This is in agreement with previous findings by Vila et al. (2000). In contrast, $\alpha$-synuclein was detectable throughout the neuropil of the substantia nigra (data not shown).

This was also the case in the striatum, nucleus accumbens, and amygdala, in which a characteristic pattern of very small $\alpha$-synuclein-positive dots was visualized with Texas Red (but not diaminobenzidine), which probably represented transected neurites or axon terminals (Figs. 5, 6). Such a punctuate pattern, consistent with accumulation of $\alpha$-synuclein in presynaptic terminals, was reported previously (Nakajo et al., 1994; Iwai et al., 1995; Hsu et al., 1998). Examination of the sections at higher magnifications revealed that $\alpha$-synuclein-positive neurites were concentrated around some $\alpha$-synucleinnegative cell bodies, in close apposition to them, resembling distinct halos around these cells (Figs. 5, 6).

To gain some insight into cell types and striatal compartments innervated by $\alpha$-synuclein-containing axons, we performed double-immunofluorescent labeling of $\alpha$-synuclein and CB. In the striatum and nucleus accumbens, $\mathrm{CB}$ is a selective marker of the matrix compartment (involved mainly in motor functions), as opposed to the patches (which are connected with limbic structures and involved in emotional functions) (Gerfen et al., 1985; Gerfen, 1992). A dense mesh of CB-immunoreactive fibers, interspersed with labeled cell bodies, was detected in the striatum and nucleus accumbens (Fig. 5). Patches of relatively low $\mathrm{CB}$ immunoreactivity were visualized in both regions. No differences in the distribution of $\alpha$-synuclein-positive neurites were observed between CBpositive and $\mathrm{CB}$-negative areas of the nucleus accumbens and dorsal striatum: multiple neurons (CB-positive or -negative) were found in both the matrix and patches, which were surrounded by $\alpha$-synuclein-positive axons (Fig. 5).

In the amygdala, $\mathrm{CB}$ is expressed by a subpopulation of GABAergic interneurons that innervate glutamatergic pyramidal projection neurons (McDonald and Mascagni, 2001; Muller et al., 2003). In agreement with this localization, we found numertwo-tailed unpaired $t$ test).

\section{striatum / nucleus accumbens}

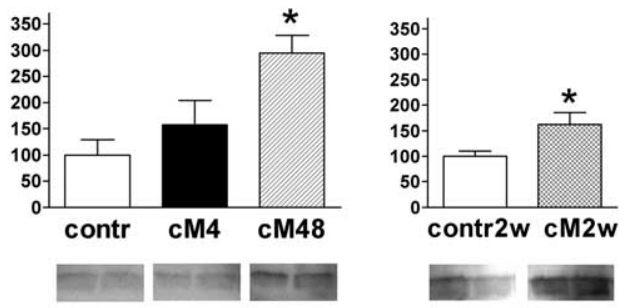

\section{amygdala}
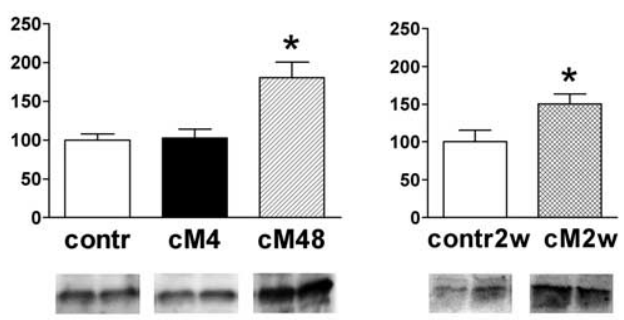

\section{mesencephalon}


Figure 4. Western blot analysis of the influence of morphine treatment and withdrawal on levels of $\alpha$-synuclein in the striatum/accumbens, amygdala, and mesencephalon. contr, Control groups injected acutely or chronically with saline and killed mice treated chronically with morphine and killed $4 \mathrm{~h}, 48 \mathrm{~h}$, and 2 weeks after the last injection, respectively. The results are $(p<0.05$ or less) versus the respective control group (cM48 vs contr by ANOVA, followed by Tukey's test; $c M 2 w$ vs contr2w by the

ous CB-positive cells in the basolateral amygdalar complex, whose $\mathrm{CB}$-containing processes surrounded multiple $\mathrm{CB}$ negative neurons forming dense basket-like structures (Fig. 6). Synuclein-positive neurites were concentrated selectively around $\mathrm{CB}$-negative cell bodies. In contrast, in the vicinity of CB-positive neurons, $\alpha$-synuclein-containing neurites were sparse or absent (Fig. 6).

\section{Discussion}

Our experiments showed that chronic morphine treatment and morphine withdrawal resulted in reduction of the $\alpha$-synuclein mRNA content in several brain regions of mice. These changes were most pronounced in the target areas of the dopaminergic mesolimbic and nigrostriatal systems and were most consistently observed after the cessation of morphine treatment, especially after a $48 \mathrm{~h}$ withdrawal. In dopaminergic cell bodies, only a slight suppression of $\alpha$-synuclein mRNA levels was detected during 



Figure 5. Localization of $\alpha$-synuclein and $\mathrm{CB}$ in the mouse dorsal striatum by double-immunofluorescent labeling. $\boldsymbol{A}, \mathrm{CB} . \boldsymbol{B}$, $\alpha$-Synuclein. $\boldsymbol{C}$, Overlay of $\boldsymbol{A}$ and $\boldsymbol{B}$ (green, (B; red, $\alpha$-synuclein) at low-power magnification (10× objective). Notice the patch/matrix distribution of (B. $\boldsymbol{D}$, CB. $\boldsymbol{E}, \alpha$-Synuclein. $\boldsymbol{F}$, Overlay of $\boldsymbol{D}$ and $\boldsymbol{E}$ (pseudocolors as above), high-power magnification of a matrix stretch ( $63 \times$ objective). $\boldsymbol{F}_{1}, \boldsymbol{F}_{2}$, Digitally enlarged fragments of $\boldsymbol{F}$ showing condensation of $\alpha$-synuclein-positive terminals around (B-positive neurons (arrows) and CB-negative cells (arrowheads).


Figure 6. Localization of $\alpha$-synuclein and $C B$ in the mouse amygdala by doubleimmunofluorescent labeling. $A, C B . B, \alpha$-Synuclein at low-power magnification $(5 \times$ objective). C, (B. D, $\alpha$-Synuclein. $\boldsymbol{E}$, Overlay of $\mathbf{C}$ and $\boldsymbol{D}$ (green, (B; red, $\alpha$-synuclein) at high-power magnification $(100 \times$ objective). The photomicrographs were taken from the basolateral amygdaloid nucleus. Arrows show some (but not all) basket-like arrangements of (B-positive terminals $(\boldsymbol{C})$, condensation of $\alpha$-synuclein-positive terminals $(\boldsymbol{D})$, and their colocalization around $\left(B\right.$-negative cell bodies $(\boldsymbol{E})$. $\boldsymbol{E}_{1}, \boldsymbol{E}_{2}$, Digitally enlarged fragments of $\boldsymbol{E}$ showing a $\mathrm{CB}$ positive neuron relatively devoid of $\alpha$-synuclein-positive innervation $\left(\boldsymbol{E}_{1}\right)$ and a $\mathrm{CB}$-negative neuron surrounded by processes positive for both $\alpha$-synuclein and $\mathrm{CB}\left(\boldsymbol{E}_{2}\right)$.

withdrawal in the VTA but not in the substantia nigra. Interestingly, Western blot analyses revealed that the $\alpha$-synuclein protein content in the striatum/accumbens and amygdala was regulated in the opposite direction from its mRNA; namely, $\alpha$-synuclein was markedly upregulated in these brain regions in mice withdrawn from chronic morphine for $48 \mathrm{~h}$. Additional experiments

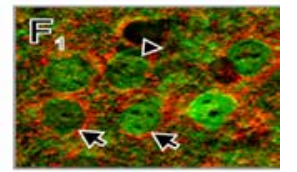

demonstrated that elevated levels of $\alpha$-synuclein persisted in the striatum/ accumbens and amygdala for 2 weeks after the cessation of chronic morphine treatment. No significant changes in $\alpha$-synuclein amount were observed in the mesencephalon of morphine-withdrawn mice, in which dopaminergic cell bodies are located.

Immunohistochemical staining revealed that $\alpha$-synuclein protein was virtually absent from the dopaminergic neuron somata, which is in agreement with a previous report (Vila et al., 2000). The protein was present at detectable amounts almost exclusively in the neuropil, both within the dopaminergic cell-body fields and in the forebrain target regions of dopaminergic projections. Such a staining pattern probably reflects accumulation of the protein in axon terminals (Nakajo et al., 1994; Iwai et al., 1995; Clayton and George, 1999). Because the striatum, nucleus accumbens, and amygdala are composed primarily of projection neurons, it is likely that the opposite changes in $\alpha$-synuclein mRNA and protein levels observed in these regions may have resulted from regulation of the mRNA and protein content in distinct neuronal populations. Although mRNA downregulated in these regions is derived from neurons whose somata are located therein, the increases in $\alpha$-synuclein levels might reflect accumulation of the protein in terminals of the afferent dopaminergic or glutamatergic pathways. Actually, most dopaminergic neurons, located in the substantia nigra, did not show significant downregulation of $\alpha$-synuclein mRNA at any time point tested; thus, they seem more likely to accumulate higher levels of $\alpha$-synuclein in their terminals innervating the forebrain than other neuronal populations, in which $\alpha$-synuclein mRNA levels were decreased. However, involvement of other neuronal pathways in the observed alterations of $\alpha$-synuclein levels cannot be excluded on the basis of the obtained results. The fact that no mRNA upregulation was detected in any of the examined brain regions suggests that the accumulation of $\alpha$-synuclein in the forebrain was attributable to alterations in posttranslational mechanisms regulating the protein stability or its transport rather than to increased gene transcription. In fact, levels of $\alpha$-synuclein depend on its phosphorylation and ubiquitination, which influence its degradation rate (Vekrellis et al., 2004). Interestingly, disparities between $\alpha$-synuclein mRNA and protein levels were reported previously during brain development and in neurodegenerative disorders associated with accumulation of $\alpha$-synuclein, in which the protein levels increased, whereas its mRNA content remained decreased or unchanged (Neystat et al., 1999; Petersen et al., 1999; Ozawa et at., 2001).

The possibility that withdrawal from chronic morphine treatment upregulated $\alpha$-synuclein in dopaminergic terminals within the striatum/accumbens and amygdala seems particularly interesting in view of the known role of dopamine in drug addictions (Di Chiara and Imperato, 1988; Nestler, 2001, 2004). $\alpha$-Synuclein upregulation could mediate important aspects of opiate action on dopaminergic cells, the function of which seems to be affected by this protein in several ways. $\alpha$-Synuclein might regulate dopamine levels, because it directly inhibits the activity of tyrosine hydroxylase and downregulates the expression of several enzymes catalyzing dopamine synthesis (Perez et al., 2002; 
Baptista et al., 2003). The protein also affects dopamine transporter activity (Lee et al., 2001; Wersinger and Sidhu, 2003). In addition, $\alpha$-synuclein might negatively regulate dopaminergic neurotransmission by slowing the rate of synaptic vesicle refilling and reducing their storage capacity, as revealed by experiments in $\alpha$-synuclein knock-out mice (Abeliovich et al., 2000; Yavich et al., 2004). Although acute administration of morphine leads to activation of the mesolimbic/nigrostriatal dopaminergic system and to increased dopamine release in the striatum/accumbens (Di Chiara and Imperato, 1988; Leone et al., 1991), opiate withdrawal is associated with decreased dopaminergic neurotransmission (Acquas et al., 1991; Pothos et al., 1991), which underlies unpleasant emotional withdrawal symptoms (Volkow et al., 2002). Thus, accumulation of $\alpha$-synuclein in mesolimbic/nigrostriatal axon terminals during morphine withdrawal could contribute to the deficiency in dopamine function by inhibiting both dopamine synthesis and its release. Both axonal localization of $\alpha$-synuclein and the prolonged nature of its accumulation show a correlation with the decreased capability of dopamine release in the striatum, which persists for several weeks after morphine withdrawal and seems to be partly caused by changes in dopaminergic terminals, because it could be observed in striatal slice preparations devoid of dopaminergic somata (Tjon et al., 1993, Ghosh et al., 1998).

Interestingly, increases in $\alpha$-synuclein levels were associated recently with actions of some other substances of abuse. Chronic cocaine was demonstrated to elevate protein levels in the human and rat brain (Brenz Verca et al., 2003; Mash et al., 2003). Furthermore, high $\alpha$-synuclein expression in the striatum and hippocampus was shown to be correlated with a genetically determined preference for alcohol in rats (Liang et al., 2003). The propensity of different drugs of abuse to upregulate $\alpha$-synuclein may suggest that this protein plays a common role in drug addictions. It could perhaps consist in mediating the deficit of the dopaminergic reward pathway activity, which is characteristic of withdrawal from various drugs of abuse and is a putative factor in predisposition to addiction (Rossetti et al., 1992; Volkow et al., 2002).

In an attempt to characterize the postsynaptic neurons innervated by $\alpha$-synuclein-containing terminals, using doubleimmunofluorescent labeling, we demonstrated that, in the striatum/accumbens, $\alpha$-synuclein-positive axons surrounded neuronal somata located both in the patches and in the matrix, as defined by CB immunolabeling. This suggests that $\alpha$-synuclein may equally affect neuronal circuits involving both striatal compartments (i.e., limbic/emotional and motor systems, respectively). However, a differential pattern of $\alpha$-synuclein innervation was observed in the BLA, in which $\alpha$-synuclein-containing terminals concentrated selectively around CB-negative cell bodies. Most CB-positive neurons present in the BLA are GABAergic interneurons, whereas most CB-negative neurons are glutamatergic projection neurons that innervate virtually all regions of the limbic striatum/nucleus accumbens and prefrontal cortex (McDonald, 1991a,b; McDonald and Mascagni, 2001; Muller et al., 2003). The selective localization of $\alpha$-synuclein-containing axon terminals around these projection neurons puts them in the position to affect the main output from the BLA to the limbic circuit.

In our experiment, the increase in $\alpha$-synuclein level in the amygdala during morphine withdrawal was extremely longlived, showing only little decay 2 weeks after the cessation of morphine treatment. It is, therefore, tempting to suggest that this may underlie some persistent amygdala-mediated effects of opi- ates. Indeed, the BLA has been implicated in conditioned aspects of addictive drug actions and control of reinstatement of drug seeking (Shalev et al., 2002; Di Ciano and Everitt, 2004). BLA inactivation prevents reinstatement of heroin self-administration elicited both by a priming dose of the opiate and by conditioned stimuli associated previously with heroin (Fuchs and See, 2002).

On the other hand, the increased $\alpha$-synuclein levels in the striatum/accumbens and amygdala could be indicative of cellular stress. $\alpha$-Synuclein has long been associated with neurodegeneration. It is prone to form oligomers, fibrillize, and precipitate, which leads to the production of intracellular inclusions, such as Lewy bodies, characteristic of Parkinson's disease and other neurodegenerative disorders, called synucleinopathies (Spillantini et al., 1997; Marti et al., 2003; Vekrellis et al., 2004). Although the formation of $\alpha$-synuclein oligomers and fibrils may require special conditions that are prerequisites for neurodegenerative pathologies, some studies suggest that the overexpression of $\alpha$-synuclein is sufficient to produce major cellular toxicity, particularly in dopaminergic neurons (Hsu et al., 2000; Saha et al., 2000; Lotharius and Brundin, 2002). Morphological changes consisting of neuronal shrinkage in the VTA and cortical volume loss have been reported after chronic opiate administration in animals and humans (Sklair-Tavron et al., 1996; Pezawas et al., 1998). Increased levels of $\alpha$-synuclein could be involved in these abnormalities.

In conclusion, we observed long-lasting increases in $\alpha$-synuclein protein levels in the forebrain regions of mice withdrawn from chronic morphine treatment. The accumulation of $\alpha$-synuclein may underlie neuronal adaptations produced by chronic exposure to opiates, including the deficiency in dopamine function during opiate withdrawal.

\section{References}

Abeliovich A, Schmitz Y, Farinas I, Choi-Lundberg D, Ho WH, Castillo PE, Shinsky N, Verdugo JM, Armanini M, Ryan A, Hynes M, Phillips H, Sulzer D, Rosenthal A (2000) Mice lacking alpha-synuclein display functional deficits in the nigrostriatal dopamine system. Neuron 25:239-252.

Acquas E, Carboni E, Di Chiara G (1991) Profound depression of mesolimbic dopamine release after morphine withdrawal in dependent rodents. Eur J Pharmacol 193:133-134.

Baptista MJ, O’Farrell C, Daya S, Ahmad R, Miller DW, Hardy J, Farrer MJ, Cookson MR (2003) Co-ordinate transcriptional regulation of dopamine synthesis genes by alpha-synuclein in human neuroblastoma cell lines. J Neurochem 85:957-968.

Brenz Verca MS, Bahl A, Boyer F, Wagner GC, Dreyer J-L (2003) Distribution of $\alpha$ - and $\gamma$-synucleins in the adult rat brain and their modification by high-dose cocaine treatment. Eur J Neurosci 18:1923-1938.

Chomczynski P, Sacchi N (1987) Single-step method of RNA isolation by acid guanidinium thiocyanate-phenol-chloroform extraction. Anal Biochem 162:156-159.

Clayton DF, George JM (1998) The synucleins: a family of proteins involved in synaptic function, plasticity, neurodegeneration and disease. Trends Neurosci 21:249-254.

Clayton DF, George JM (1999) Synucleins in synaptic plasticity and neurodegenerative disorders. J Neurosci Res 58:120-129.

Di Chiara G, Imperato A (1988) Drugs abused by humans preferentially increase synaptic dopamine concentrations in the mesolimbic system of freely moving rats. Proc Natl Acad Sci USA 85:5274-5278.

Di Chiara G, North RA (1992) Neurobiology of opiate abuse. Trends Pharmacol Sci 13:185-193.

Di Ciano P, Everitt BJ (2004) Direct interactions between the basolateral amygdala and nucleus accumbens core underlie cocaine-seeking behavior by rats. J Neurosci 24:7167-7173.

Fuchs RA, See RE (2002) Basolateral amygdala inactivation abolishes conditioned stimulus- and heroin-induced reinstatement of extinguished heroin-seeking behavior in rats. Psychopharmacology 160:425-433. 
Gerfen CR (1992) The neostriatal mosaic: multiple levels of compartmental organization. Trends Neurosci 4:133-139.

Gerfen CR, Baimbridge KG, Miller JJ (1985) The neostriatal mosaic: compartmental distribution of calcium-binding protein and parvalbumin in the basal ganglia of the rat and monkey. Proc Natl Acad Sci USA 82:8780-8784.

Ghosh S, Patel AH, Cousins M, Grasing K (1998) Different effects of opiate withdrawal on dopamine turnover, uptake, and release in the striatum and nucleus accumbens. Neurochem Res 23:875-885.

Hong L, Ko HW, Gwag BJ, Joe E, Lee S, Kim Y-T, Suh Y-H (1998) The cDNA cloning and ontogeny of mouse $\alpha$-synuclein. NeuroReport 9:1239-1242.

Hsu LJ, Mallory M, Xia Y, Veinbergs I, Hashimoto M, Yoshimoto M, Thal LJ, Saitoh T, Masliah E (1998) Expression pattern of synucleins (non-A $\beta$ component of Alzheimer's disease amyloid precursor protein $/ \alpha$ synuclein) during murine brain development. J Neurochem 71:338-344.

Hsu LJ, Sagara Y, Arroyo A, Rockenstein E, Sisk A, Mallory M, Wong J, Takenouchi T, Hashimoto M, Masliah E (2000) Alpha-synuclein promotes mitochondrial deficit and oxidative stress. Am J Pathol 157:401-410.

Hyman SE, Malenka RC (2001) Addiction and the brain: the neurobiology of compulsion and its persistence. Nat Rev Neurosci 2:695-703.

Iwai A, Masliah E, Yoshimoto M, Ge N, Flanagan L, de Silva HAR, Kittel A, Saitoh T (1995) The precursor protein of non-A $\beta$ component of Alzheimer's disease amyloid is a presynaptic protein of the central nervous system. Neuron 14:467-475.

Lee FJ, Liu F, Pristupa ZB, Niznik HB (2001) Direct binding and functional coupling of alpha-synuclein to the dopamine transporters accelerate dopamine-induced apoptosis. FASEB J 15:916-926.

Leone P, Pocock D, Wise RA (1991) Morphine-dopamine interaction: ventral tegmental morphine increases nucleus accumbens dopamine release. Pharmacol Biochem Behav 39:469-472.

Liang T, Spence J, Liu L, Strother WN, Chang HW, Ellison JA, Lumeng L, Li TK, Foroud T, Carr LG (2003) $\alpha$-Synuclein maps to a quantitative trait locus for alcohol preference and is differentially expressed in alcoholpreferring and -nonpreferring rats. Proc Natl Acad Sci USA 100:4690-4695.

Lotharius J, Brundin P (2002) Pathogenesis of Parkinson's disease: dopamine, vesicles and alpha-synuclein. Nat Rev Neurosci 3:932-942.

Maroteaux L, Scheller RH (1991) The rat brain synucleins; family of proteins transiently associated with neuronal membrane. Brain Res Mol Brain Res 11:335-343.

Marti MJ, Tolosa E, Campdelacreu J (2003) Clinical overview of the synucleinopathies. Mov Disord 18 [Suppl 6]:S21-S27.

Mash DC, Ouyang Q, Pablo J, Basile M, Izenwasser S, Lieberman A, Perrin RJ (2003) Cocaine abusers have an overexpression of $\alpha$-synuclein in dopamine neurons. J Neurosci 23:2564-2571.

McDonald AJ (1991a) Organization of the amygdaloid projections to the prefrontal cortex and associated striatum in the rat. Neuroscience 44:1-14.

McDonald AJ (1991b) Topographical organization of amygdaloid projections to the caudatoputamen, nucleus accumbens, and related striatal-like areas of the rat brain. Neuroscience 44:15-33.

McDonald AJ, Mascagni F (2001) Colocalization of calcium-binding proteins and GABA in neurons of the rat basolateral amygdala. Neuroscience 105:681-693.

Muller JF, Mascagni F, McDonald AJ (2003) Synaptic connections of distinct interneuronal subpopulations in the rat basolateral amygdalar nucleus. J Comp Neurol 456:217-236.

Nakajo S, Shioda S, Nakai Y, Nakaya K (1994) Localization of phosphoneuroprotein 14 (PNP 14) and its mRNA expression in rat brain determined by immunocytochemistry and in situ hybridization. Brain Res Mol Brain Res 27:81-86.

Nestler E (2001) Molecular basis of long-term plasticity underlying addiction. Nat Rev Neurosci 2:119-128.

Nestler E (2004) Historical review: molecular and cellular mechanisms of opiate and cocaine addiction. Trends Pharmacol Sci 25:210-218.

Neystat M, Lynch T, Przedborski S, Kholodilov N, Rzhetskaya M, Burke RE (1999) Alpha-synuclein expression in substantia nigra and cortex in Parkinson's disease. Mov Disord 14:417-422.

Ozawa T, Okuizumi K, Ikeuchi T, Wakabayashi K, Takahashi H, Tsuji S (2001) Analysis of the expression level of alpha-synuclein mRNA using postmortem brain samples from pathologically confirmed cases of multiple system atrophy. Acta Neuropathol (Berl) 102:188-190.

Perez RG, Waymire JC, Lin E, Liu JJ, Guo F, Zigmond MJ (2002) A role for $\alpha$-synuclein in the regulation of dopamine biosynthesis. J Neurosci 15:3090-3099.

Petersen K, Olesen OF, Mikkelsen JD (1999) Developmental expression of $\alpha$-synuclein in rat hippocampus and cerebral cortex. Neuroscience 91:651-659.

Pezawas LM, Fischer G, Diamant K, Schneider C, Schindler SD, Thurnher M, Ploechl W, Eder H, Kasper S (1998) Cerebral CT findings in male opioid-dependent patients: stereological, planimetric and linear measurements. Psychiatry Res 83:139-147.

Pothos E, Rada P, Mark GP, Hoebel BG (1991) Dopamine microdialysis in the nucleus accumbens during acute and chronic morphine, naloxoneprecipitated withdrawal and clonidine treatment. Brain Res 566:348-350.

Rossetti ZL, Hmaidan Y, Gessa GL (1992) Marked inhibition of mesolimbic dopamine release: a common feature of ethanol, morphine, cocaine and amphetamine abstinence in rats. Eur J Pharmacol 221:227-234.

Saha AR, Ninkina NN, Hanger DP, Anderton BH, Davies AM, Buchman VL (2000) Induction of neuronal death by alpha-synuclein. Eur J Neurosci 12:3073-3077.

Shalev U, Grimm JW, Shaham Y (2002) Neurobiology of relapse to heroin and cocaine seeking: a review. Pharmacol Rev 54:1-42.

Sklair-Tavron L, Shi W-X, Lane SB, Harris HW, Bunney BS, Nestler EJ (1996) Chronic morphine induces visible changes in the morphology of mesolimbic dopamine neurons. Proc Natl Acad Sci USA 93:11202-11207.

Spillantini MG, Schmidt ML, Lee VM, Trojanowski JQ, Jakes R, Goedert M (1997) Alpha-synuclein in Lewy bodies. Nature 388:839-840.

Sutcliffe JG, Foye PE, Erlander MG, Hilbush BS, Bodzin LJ, Durham JT, Hasel KW (2000) TOGA: an automated parsing technology for analyzing expression of nearly all genes. Proc Natl Acad Sci USA 97:1967-1981.

Tjon GHK, De Vries TJ, Wardeh G, Hogenboom F, Mulder AH, Schoffelmeer ANM (1993) Long-lasting reciprocal changes in striatal dopamine and acetylcholine release upon morphine withdrawal. Eur J Pharmacol 235:321-322.

Vekrellis K, Rideout HJ, Stefanis L (2004) Neurobiology of $\alpha$-synuclein. Mol Neurobiol 30:1-22.

Vila M, Vukosavic S, Jackson-Lewis V, Neystat M, Jakowec M, Przedborski S (2000) $\alpha$-Synuclein up-regulation in substantia nigra dopaminergic neurons following administration of the parkinsonian toxin MPTP. J Neurochem 74:721-729.

Volkow ND, Fowler JS, Wang G-J, Goldstein RZ (2002) Role of dopamine, the frontal cortex and memory circuits in drug addiction: insight from imaging studies. Neurobiol Learn Mem 78:610-624.

Wersinger C, Sidhu A (2003) Attenuation of dopamine transporter activity by alpha-synuclein. Neurosci Lett 340:189-192.

Yavich L, Tanila H, Vepsalainen S, Jakala P (2004) Role of $\alpha$-synuclein in presynaptic dopamine recruitment. J Neurosci 24:11165-11170.

Young III WS, Bonner TI, Brann MR (1986) Mesencephalic dopamine neurons regulate the expression of the neuropeptide mRNAs in the rat forebrain. Proc Natl Acad Sci USA 83:9827-9831. 